\title{
Students' Opinions on the Theoretical Aspects of Nursing Education in Turkey
}

(1) Leyla Muslu1, (1) Süreyya Sarvan¹, (1) IIhan Günbayı²

${ }^{1}$ Akdeniz University, Faculty of Nursing, Antalya, Turkey

2Akdeniz University, Faculty of Education, Antalya, Turkey

\section{Abstract}

BACKGROUND/AIMS: In recent years, nursing education has attempted to transition to a student-centered curriculum; however, the nursing education system needs to renew itself and adapt to changing conditions. Therefore, the perceptions, opinions, and recommendations of the students, who are the cornerstones of education, in the changing process are important. This study aimed to reveal the opinions of nursing students on the theoretical aspect of nursing education.

MATERIALS and METHODS: This descriptive qualitative study with a holistic single-case design was conducted with a total of 14 students. Interviews were conducted using a semi-structured interview form. The thematic descriptive and content analysis method was used to analyze the obtained data.

RESULTS: Thematic analyses revealed that the most important theme was that a theoretical lesson is conducted 8 hours a day. Among the 14 metaphors produced by the students about the theoretical aspect of nursing education, a positive feature was mentioned only in one.

CONCLUSION: Study results may guide decisions, such as planning course catalogs and curriculums. Additionally, students' views can contribute to the conducted studies to improve and develop nursing education.

Keywords: Nursing education; theoretical course; case study

\section{INTRODUCTION}

Nursing education and practice have passed through various stages so far in Turkey. Despite improvements in nursing education, some problems are determined in this process. Nursing education has problems in finding qualified and sufficient teaching staff, using modern teaching methods in the courses, and objectively evaluating the learners. ${ }^{1,2}$ This study aimed to understand the perceptions of final year students on theoretical education and the problems they experienced in learningand put forward suggestions for solutions.

Recently, nursing education is changing toward a studentcentered curriculum, thus the education system has to respond to the self-renewal, changing conditions, needs, and expectations. However, globally, nursing education is reported as inadequately competent due to insufficient strategic leadership, the static and rigid curriculum of nursing faculties, and inadequate resources. ${ }^{3-6}$

To cite this article: Muslu L, Sarvan S, Günbayı I. Students' Opinions on the Theoretical Aspects of Nursing Education in Turkey.

Cyprus J Med Sci 2021;6(Suppl 1):48-57

ORCID iDs of the authors: L.M. 0000-0003-1024-8352; S.S. 0000-0002-6828-1780; I.G. 0000-0001-7139-0200. 
Therefore, nursing education, management, accreditation, and learning systems need to be developed worldwide. ${ }^{5}$ Additionally, revealing the students' views on the experiences of nursing students could contribute to the re-construction of nursing education.

The results of this study are expected to contribute to the proposals for theoretical nursing education. Therefore, the following questions were sought to answer:

- What are the experiences of students in theoretical courses?

- What are the problems that students face regarding theoretical courses?

- What are students' recommendations for the development of theoretical courses?

- What do the students think theoretical courses are like? Why?

\section{Background}

The nursing workforce has a key role in the functioning of the health care system. Health care workers provided great support to health and development in the last century. However, the changing needs of health care in the $21^{\text {st }}$ century suggest that nursing education should be subjected to different developments. ${ }^{5}$ Improvements in nursing education are considered as the basis for increasing the quality of health and care systems. ${ }^{5,7,8}$ Nursing education should provide the students with the knowledge, skill, attitude, behavior, decision making, and application ability, which form the basis of nursing practice and factors that constitute the nursing profession, such as evaluation and monitoring of innovations. ${ }^{9}$

In nursing education programs, theory and practice are integrated conducted. Students get the necessary theoretical information at school; however, they also try to improve their clinical judgment ability by transferring the theoretical knowledge to practice to transform the information to the behavior and learn the whats, whys, and hows. ${ }^{8,9}$ Experiences, expectations, and recommendations of the students about theoretical and practical education can contribute to the more effective nursing educational processes. However, knowledge and researches in the education of health professionals are insufficient. ${ }^{5}$

Nursing education in Turkey is based on a 4-year or 4,600-h theoretical and clinical training. At least one-third of the total educational period is theoretical and the rest is clinical. In Turkey, 124 are in nursing undergraduate programs and 71,538 students are registered to those programs. Similar problems are experienced in nursing education in Turkey with the rest of the countries worldwide. Solving those problems will impact the development and maintenance of community health, as well as contribute to the nursing profession. ${ }^{10}$

The review of related literature identified limited qualitative studies on the theoretical aspect of nursing education. Thus, study results can contribute to the planning, implementation, and evaluation of the theoretical aspect of nursing education.

\section{MATERIALS and METHODS}

\section{Design}

This study is a qualitative study with a descriptive and holistic single-case design. Descriptive case studies are one of the most common qualitative studies, which can provide an understanding of individuals' world perceptions and seek insights. ${ }^{11}$ Case studies can establish cause and effect by observing effects in real contexts, recognizing that context is a powerful determinant of both causes and effects. Further, case studies investigate and report the complex dynamic and unfolding interactions of events, human relations, and other factors in a unique instance. ${ }^{12}$

\section{Participants}

This study consisted of 977 nursing students who study in the Faculty of Nursing in a university in the academic year 2017. The sample selection was based on a purposeful sampling method, and two volunteer participants were selected from each major department (surgical nursing, internal medicine nursing, obstetrics and gynecology nursing, child health and diseases nursing, psychiatric nursing, public health nursing, and management nursing), making a total of 14 participants. An equal number of students from each gender in the final year was also taken into consideration to determine the participants. Thus, interviews were done with those 14 volunteer students from the final year.

\section{Data Collection}

Data were collected by researchers from April-May 2017. An interview form consisting of four open-ended semi-structured questions was used. This included 45-min recorded interviews with participants using initial interview questions. Participants were encouraged to freely express their own opinions during the interview. The in-depth interview technique was conducted in the qualitative data collection, and a suitable environment was created for students to freely express their experiences and views related to their theoretical education. All interviews were conducted in a separate room, and participants' experiences, thoughts, and feelings were recorded in a taped diary after obtaining the participant's verbal and written consents.

\section{Data Collection Tools}

Individual information form: An individual information form prepared by researchers involving nine questions related to 
the socio-demographic characteristics (age, educational status, family information, etc.) of the study participants was used.

Semi-structured interview form: A conceptual framework was created from the conducted field study to prepare the semistructured interview form. Later on, preliminary discussions wereheld and opinions of experts were obtained and questions, which were taken into account in preparing the final question form, were selected. The questions were open-ended and semistructured for them to be answered and re-configured with the received responses to lead to new questions. The semi-structured interview form with four questions was based on the experiences of the nursing education in theoretical aspects and problems that are experienced and how they coped with those problems and their suggestions. Semi-structured interviews were used because they would provide an in-depth exploration of the topic and allow the researchers flexibility, e.g., to change the order of questions, simplify the questions, and probe the interviews. ${ }^{12}$

\section{Statistical Analysis}

Data analysis started with repeated readings of interview transcripts from interviews with the nursing students to determine the essence of the phenomenon and structures of experiences of nursing students related to theoretical aspect and understand the influences of this kind of training on final year nursing students. During data analysis, the data were categorically and chronically organized, repeatedly reviewed, and continually coded. Interview transcripts were regularly reviewed, themes were arranged, and findings were interpreted..$^{12}$

Additionally, the data analysis process was aided using a qualitative data analysis computer program called NVIV011. These kinds of computer programs do not perform the analysis but facilitate and assist it by organizing data and recodes and nodes, etc. ${ }^{12}$

\section{Validity and Reliability}

Five steps were followed to ensure reliability and validity of the study: (i) data were collected from semi-structured interviews based on related literature and data were categorically and chronically organized, repeatedly reviewed, and continually coded, (ii) data were used as direct quotations from the interviews without making any comments on them, (iii) a purposive sampling method based on voluntarism was used to get opinions and experiences of nursing students, (iv) data were coded by two independent researchers and Cohen's Kappa coefficient was calculated to determine the inter-rater reliability of themes coded as -0.773 perfect agreement for inner reliability, and (v) records of interviews were kept for outer reliability.

\section{Ethical Consideration}

The study was initiated with the permission of the Faculty of Nursing and the approval of the ethics committee of clinical researches. Participants were briefed about the research aims, kept informed at all stages, and offered anonymity. A consent form was signed between the researcher and each participant on the use of data for analysis to be reported and disseminated. The researcher was careful not to impose their belief on others and wassecondary, and the participants' opinion was required.

\section{RESULTS}

Of the 14 participants, seven were females, the average age was $22.21 \pm 0.69$ years (min: 21 , max: 24$)$, eight had a mother and seven had a father who was a primary school graduate, and seven had two brothers. Of them, nine resided in dormitories and 11 had incomes that equaled their expenses. The Grade Point Average of students was $2.68 \pm 0.269$ (min: 2.30 , max: 3.10).

Based on the qualitative findings from the interviews with the participants, the problems, factors, recommendations, and metaphors associated with theoretical education consisted of main themes and their sub-themes.

\section{Problems in Theoretical Education}

The thematic frequency of nursing students' opinions regarding the problems experienced in theoretical education was categorized to find out the response to the problems in theoretical education. As seen in Table 1 from the opinions of the students on the problems they experienced in theoretical education; 13/14 (92.86\%) students complained about blockscheduling of courses (theoretical courses 8 hour a day). Some participants' views on that are as follows:

It is difficult, it is difficult. We come in the morning and return in the evening. We become verytired in the evening and we can't do anything, we just go to sleep. We get up early and again, does the same thing $(K 3,1,1)$.

Compressed. I mean, it's too compressed for normal lesson hours. You know, you want to get all of it, but I can't seem to keep up with this... I know, I sleep a lot in class in most of the courses $(K 4,1,1)$.

Complains about the problems with teaching courses were expressed by $8 / 14$ (57.14\%) students as follows:

I think that the lecture notes are very inadequate as a way of expression... There are no cases in course notes. What is missing is the fact that the information in the lecture notes is not visualized in my eyes $(K 8,1,2)$. 
Moreover, if the lecturer can get a little more into the student level, it will be very good too... They know a lot of information, but there are problems with teaching what they know $(K 10,1,2)$.

Complaints about physical conditions were expressed by $7 / 14$ (50\%) students. One of the participants' views is as follows:

Other problems... When the class is crowded, there is noise. We cannot hear much when we sit on desks far from the board and the instructor. These things happen... Sometimes, things can be a problem, while using projectors, technical problems can occur, and fixing it up takes time $(K 2,1,3)$.

Problems originating from the students were mentioned by $6 / 14$ (42.9\%) students. One of the participants' views on that is as follows:

We are 270 students but we are not united. If we want to do something here, to reflect modern nursing, I must do it with the support of my friends, but I can't find it $(K 1,1,4)$.

Instructors' insufficient effective class management is expressed by $5 / 14(35,71 \%)$ students. Some participants' views on that are as follows:

Our problem is that the number of students is too many. I think the lecturers should have more control over the classes $(K 11,1,5)$.

Some of our lessons were very boring since some lecturers have taught in a boring way, making us bored $(K 14,1,5)$.

Maybe, the lecturers need to develop themselves in this regard. The lectures in class should neither control students too much nor ignore students in class. The lecturer must be both be loving, with humor, and make students listen $(K 6,1,5)$.

The problems with measurement and evaluation of students were mentioned by $4 / 14$ (28.6\%) students. One of the participant's views on that is as follows:

We are also expecting that nursing care should be asked during exams; however, generally, among the 50-exam questions, 15 are on nursing care, the rest are on illnesses $(K 1,1,6)$.

Problems, such as inadequate and expensive textbooks, nursing education are being far from making the students enjoy the nursing profession, the course hours' being divided among different teaching staff, and the insufficiency of nursing aspect in the subjects of courses was mentioned by 1/14 (7.1\%) student. Some participant's views on those are as follows:

... First of all, we do not have a source to study on, apart from the course notes, few nursing notebooks are on sale and are very expensive $(K 14,1,7)$.

A difference is observed between senior lecturers and lecturers in theoretical courses. That is to say if, in a program, there are too many senior lecturers, lecturers do not have many courses and usually, the courses they teach are the courses that senior lecturers do not want to teach $(K 1,1,9)$.

When we generally interpret the participants' views on the theoretical education problems, it is understood from the participant's view that the block-scheduling of courses is the main problem to be resolved. Additionally, problems related to teaching courses and problems due to physical setting were also emphasized more than others.

Table 1. Thematic analysis of problems at theoretical education

\begin{tabular}{|c|c|c|c|c|c|c|c|c|c|c|c|c|c|c|c|c|c|}
\hline $\mathrm{n}$ & Problems at theoretical education & $\overline{\underline{z}}$ & $\underline{\simeq}$ & $\underline{\underline{n}}$ & $\ddot{ \pm}$ & $\underline{\underline{n}}$ & $\underline{\underline{\varphi}}$ & $\underline{\underline{1}}$ & $\underline{\ddot{Q}}$ & $\ddot{q}$ & $\stackrel{\circ}{\underline{I}}$ & $\overline{\bar{E}}$ & $\stackrel{\mathfrak{Z}}{\underline{z}}$ & $\stackrel{m}{\underline{\underline{n}}}$ & $\frac{\nabla}{\bar{x}}$ & $f$ & $\%$ \\
\hline 1 & Block-schedulling of courses & $\sqrt{ }$ & $\sqrt{ }$ & $\sqrt{ }$ & $\sqrt{ }$ & $\sqrt{ }$ & $\sqrt{ }$ & $\sqrt{ }$ & $\sqrt{ }$ & & $\sqrt{ }$ & $\sqrt{ }$ & $\sqrt{ }$ & $\sqrt{ }$ & $\sqrt{ }$ & 13 & 92.86 \\
\hline 2 & Problems with teaching courses & $\sqrt{ }$ & & & $\sqrt{ }$ & $\sqrt{ }$ & & & $\sqrt{ }$ & $\sqrt{ }$ & & $\sqrt{ }$ & $\sqrt{ }$ & & $\sqrt{ }$ & 8 & 57.14 \\
\hline 3 & Problems due to physical setting & $\sqrt{ }$ & $\sqrt{ }$ & $\sqrt{ }$ & & & $\sqrt{ }$ & & & $\sqrt{ }$ & & $\sqrt{ }$ & & $\sqrt{ }$ & & 7 & 50.00 \\
\hline 4 & Problems originating from the students & $\sqrt{ }$ & & $\sqrt{ }$ & & $\sqrt{ }$ & & & $\sqrt{ }$ & & $\sqrt{ }$ & & & & $\sqrt{ }$ & 6 & 42.86 \\
\hline 5 & $\begin{array}{l}\text { Instructors' lack of managing the class } \\
\text { effectively }\end{array}$ & $\sqrt{ }$ & & & & & $\sqrt{ }$ & & $\sqrt{ }$ & & & & & $\sqrt{ }$ & $\sqrt{ }$ & 5 & 35.71 \\
\hline 6 & $\begin{array}{l}\text { Problems with measurement and } \\
\text { evaluation of students }\end{array}$ & $\sqrt{ }$ & & & $\sqrt{ }$ & & & & & & & & & $\sqrt{ }$ & $\sqrt{ }$ & 4 & 28.57 \\
\hline 7 & Inadequate and expensive textbooks & & & & & & & & & & & & & & $\sqrt{ }$ & 1 & 7.14 \\
\hline 8 & $\begin{array}{l}\text { Nursing education's being far from } \\
\text { making the students enjoy nursing } \\
\text { profession }\end{array}$ & & & & $\sqrt{ }$ & & & & & & & & & & & 1 & 7.14 \\
\hline 9 & $\begin{array}{l}\text { The course hours' being divided } \\
\text { among different teaching staff }\end{array}$ & $\sqrt{ }$ & & & & & & & & & & & & & & & 7.14 \\
\hline 10 & $\begin{array}{l}\text { The insufficiency of nursing aspect in } \\
\text { the subjects of courses }\end{array}$ & $\sqrt{ }$ & & & & & & & & & & & & & & 1 & 7.14 \\
\hline
\end{tabular}




\section{Factors Facilitating Theoretical Education}

The thematic frequency of nursing students' opinions regarding the factors that facilitate theoretical education was categorized to find out its response. As seen in Table 2 from the opinions of the students on factors facilitating theoretical education, 5/14 (35.7\%) students mentioned theoretical education completion with laboratorypractice. Some participants' views on that are as follows:

In other words, the immediate practice of theoretical courses makes it easier to understand $(K 6,2,1)$.

I am pleased that what is taught is practiced in the lab. This is $\operatorname{good}(K 7,2,1)$.

I see the lab as the biggest step before the internship... I think that if I go out of the laboratory without doing modeling, I will have difficulty in my internship (K13, 2,1).

Laboratory practices are certainly very useful... For example, we have the process steps in the laboratory, or even they are really useful for our clinical practice $(K 14,2,1)$.

Attending theoretical courses before the clinical practice was mentioned by 2/14 (14.2) participants. Some participants' views on that are as follows:

And I think it's a good thing that before we start practicing, we should first attend courses in theory $(K 1,2.2)$.

As I said, since theoretical courses are presented before we start practicing, it makes me more comfortable during practice, and of course, I also learn things that I do not know $(K 14,2,2)$.
The description of clinical experiences by lecturers in the course, classification of the curriculum according to the principle from simple to complex, the sufficiency of physical conditions and technical equipment, and using remarkable methods in teaching was mentioned by 1/14 (14.2) participant as follows:

While the lecturers tell their experiences with the patients, I directly see myself in the stories they tell. At that moment, when I put myself in that feeling, I realize that I am really in a sacred profession (K10,2, 3).

I think it's helpful to attend the courses at these stages...I think that it is very good and logical to go on first, the fundamentals of nursing, then internal medicine nursing, surgical nursing, etc. (K14,2,4).

When we generally interpret the participants' views on factors that facilitate the theoretical education, they stressed the practice aspect of nursing education, such as theoretical training completion with laboratory practice and clinical experiences description by lecturers in the course. Then they were also concerned with the technical and physical conditions of the theoretical courses, classification of the curriculum according to the principle from simple to complex, and remarkable methods inteaching.

\section{Recommendations for Theoretical Education}

The thematic frequency of nursingstudents' recommendations for theoretical education was categorized to find out recommendations for theoretical education (Table 3).

As understood from participants' recommendations for theoretical education, 11/14 (78.57\%) participants suggested

Table 2. Thematic analysis related to factors facilitating theoretical education

\begin{tabular}{|c|c|c|c|c|c|c|c|c|c|c|c|c|c|c|c|c|c|}
\hline$n$ & $\begin{array}{l}\text { Factors facilitating } \\
\text { theoretical education }\end{array}$ & $\Xi$ & $\underline{N}$ & $\underline{m}$ & 士 & $\underline{\underline{n}}$ & $\underline{\underline{ }}$ & $\underline{1}$ & $\stackrel{\infty}{\underline{1}}$ & $\underline{\theta}$ & $\stackrel{0}{\underline{x}}$ & $\check{E}$ & $\underset{\check{V}}{\simeq}$ & $\frac{m}{\check{z}}$ & $\underset{\Xi}{ \pm}$ & $f$ & $\%$ \\
\hline 1 & $\begin{array}{l}\text { Completion of theoretical } \\
\text { education with laboratory } \\
\text { practice }\end{array}$ & & & & & $\sqrt{ }$ & $\sqrt{ }$ & & & & $\sqrt{ }$ & & & $\sqrt{ }$ & $\sqrt{ }$ & 5 & 35.7 \\
\hline 2 & $\begin{array}{l}\text { Attending theoretical courses } \\
\text { before clinical practice }\end{array}$ & $\sqrt{ }$ & & & & & & & & & & & & $\sqrt{ }$ & & 2 & 14.2 \\
\hline 3 & $\begin{array}{l}\text { Description of clinical } \\
\text { experiences by lecturers in the } \\
\text { course }\end{array}$ & & & & & & & & & & & $\sqrt{ }$ & & & & 1 & 7.14 \\
\hline 4 & $\begin{array}{l}\text { Classification of the curriculum } \\
\text { according to the principle from } \\
\text { simple to complex }\end{array}$ & & & & & & & & & & & & & & $\sqrt{ }$ & 1 & 7.14 \\
\hline 5 & $\begin{array}{l}\text { Sufficiency of physical } \\
\text { conditions and technical } \\
\text { equipments }\end{array}$ & $\sqrt{ }$ & & & & & & & & & & & & & & 1 & 7.14 \\
\hline 6 & $\begin{array}{l}\text { Using of remarkable methods } \\
\text { in teaching }\end{array}$ & & & & & & & & & & & & & $\sqrt{ }$ & & 1 & 7.14 \\
\hline
\end{tabular}


that some teaching methods should be used to enhance learning.

Some participants' views on that are as follows:

I still think that some information in courses has not been updated for us. On some slides, we find some differences among the suggested references... The education in the theoretical courses should be a little more updated $(K 1,3,1)$.

Sometimes expressions are insufficient, we use our imagination, that is, images in the courses are more effective... it can be a video or a photo. Things like that... I think it's much improved with laboratory. The lecturers should discuss with the students what they teach, otherwise, we don't learn but memorize $(K 5,3,1)$.

I want teachers to do things like a 5-min role-play to attract students' attention in courses (K13,3,1).

Block-scheduling of courses should be given up as suggested by 9/14 $(64,3 \%)$ participants. Some participants' views on that are as follows:

It will be better to have longer breaks. Because having a class for 8 $h$ is a bit difficult $(K 1,3,2)$.

The number of laboratory practices should be increased... I think it is necessary to put the theories into practice $(K 13,3,3)$.

Laboratory practices should be more effective as suggested by $6 / 14$ (42,9\%) participants. One of the participants' views on that is as follows:

Because in laboratory practices, we feel that we learn more. What is taught in theoretical courses in $2 \mathrm{~h}$ can be taught in laboratories about in 10 min in all details. It is more didactic. Thus, practices in laboratories are better $(K 9,3,3)$.

The number of students per classroom should be reduced as suggested by $4 / 14$ (28.6\%) participants. One of the participants' views on that is as follows:

My suggestion for the effectiveness of theoretical courses is that the number of students perclass should be reduced $(K 1,3,4)$.

Positive feedback should be given to students in the courses as suggested by $3 / 14$ (21.4\%) participants. One participant's view on that is as follows:

Unlike some lecturers, some are very open-minded to our ideas. They say that they will considerwhether our ideas are appropriate or not, which positively motivates us $(K 11,3,5)$.

The teaching of course topics should be carried out with case reports as suggested by $2 / 14$ (14.3\%) participants. One of the participant's views on that is as follows:

I think courses should be carried out with case reports. There must be a case report at the end of each course, I mean, while explaining a topic of a course. Thus, we learn much better with it $(K 8,3,6)$.

Courses should be summarized at the end, that there should be no obligation for course attendance, and that courses should have standardized measurement and evaluation as suggested by $1 / 14(7.1 \%)$ participants. One of the participant's views on that is as follows:

During the last $10 \mathrm{~min}$ of the course, summarizing the whole course and revisions by lecturers are very useful instead of checking

Table 3. Thematic analysis of recommendations for theoretical education

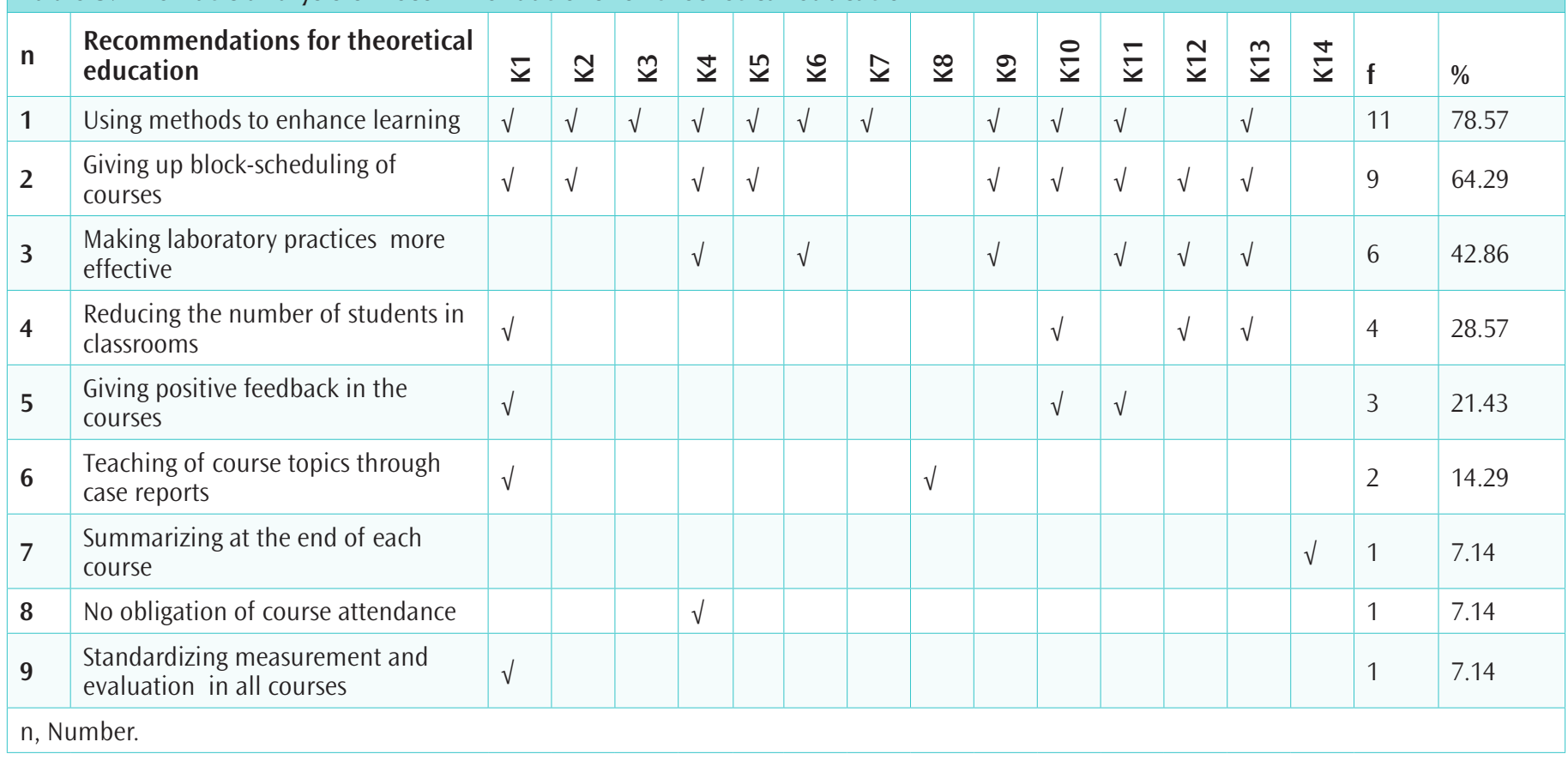


students by questions whether they have learned ornot (K14, 3, 7).

When we generally interpret the participants' suggestions on theoretical education, they first stressed on the importance that some teaching methods should be used to enhance the effectiveness of learning in class. Additionally, they also forwarded suggestions for longer breaks among courses instead of scheduling, that the number of students per classroom should be reduced, and that there should be more laboratory practice, which is a bridge between theoretical and practical in nursing education.

\section{Thematic Analysis of Metaphors on Theoretical Education}

As seen in Figure 1, according to metaphors on the theoretical education of students in the nursing faculty, four were under plants theme including tree, snowdrop, the tree half of which leaves fell and pomegranate; three under machine theme including non-stop watch, projection and machine; two under the cybernetic theme including computer software and robot; animal theme including the bird in cage and sheep flock; one under the human theme including clown ;and under other theme including disposable goods.

When generally analyzed, the students reported eight negative metaphors about the theoretical aspect of nursing education, four no positive or negative judgment, and one positive. For instance, thestudent who produced the positive metaphor used the "snowdrop" flower that grows even in hard a condition just as to train nursing students is a long and hard process.

\section{DISCUSSION}

This study qualitatively analyzed the problems, factors, and recommendations for theoretical education in nursing and metaphors by nursing students for their opinions based on their perspectives via thematic, descriptive, frequency, and content analysis.

This study understood that the block-scheduling of courses was the most important problem based on the results of the participant's views on the problems in theoretical education. This finding is consistent with the studies by Bagcivan et al. ${ }^{7}$ and Burnard et al. ${ }^{12}$ that revealed that intensive and day-long course hours are an important source of stressors for nursing students.

Additionally, problems with teaching courses and physical settings were of priority. Accordingly, in the study on nursing faculty students by Bagcivan et al. ${ }^{7}$, monotonous, boring courses, and problems originating from the physical setting were the factors that were mentioned as sources of stress by nursing students. One of the problems mentioned in the 2017 nursing education workshop that was reported by the Council of Higher Education, ${ }^{9}$ was that the development of students' advanced cognitive talents, such as analysis, synthesis, and evaluation, is limited due to the theoretical courses that are taught with expository instruction method without question and answer, and discussion techniques instead of interactive teaching methods, which are parallel with our study results. Contrarily, participants mentioned the experiences related to the problems that originate fromstudents, which showed that they self-criticize themselves.

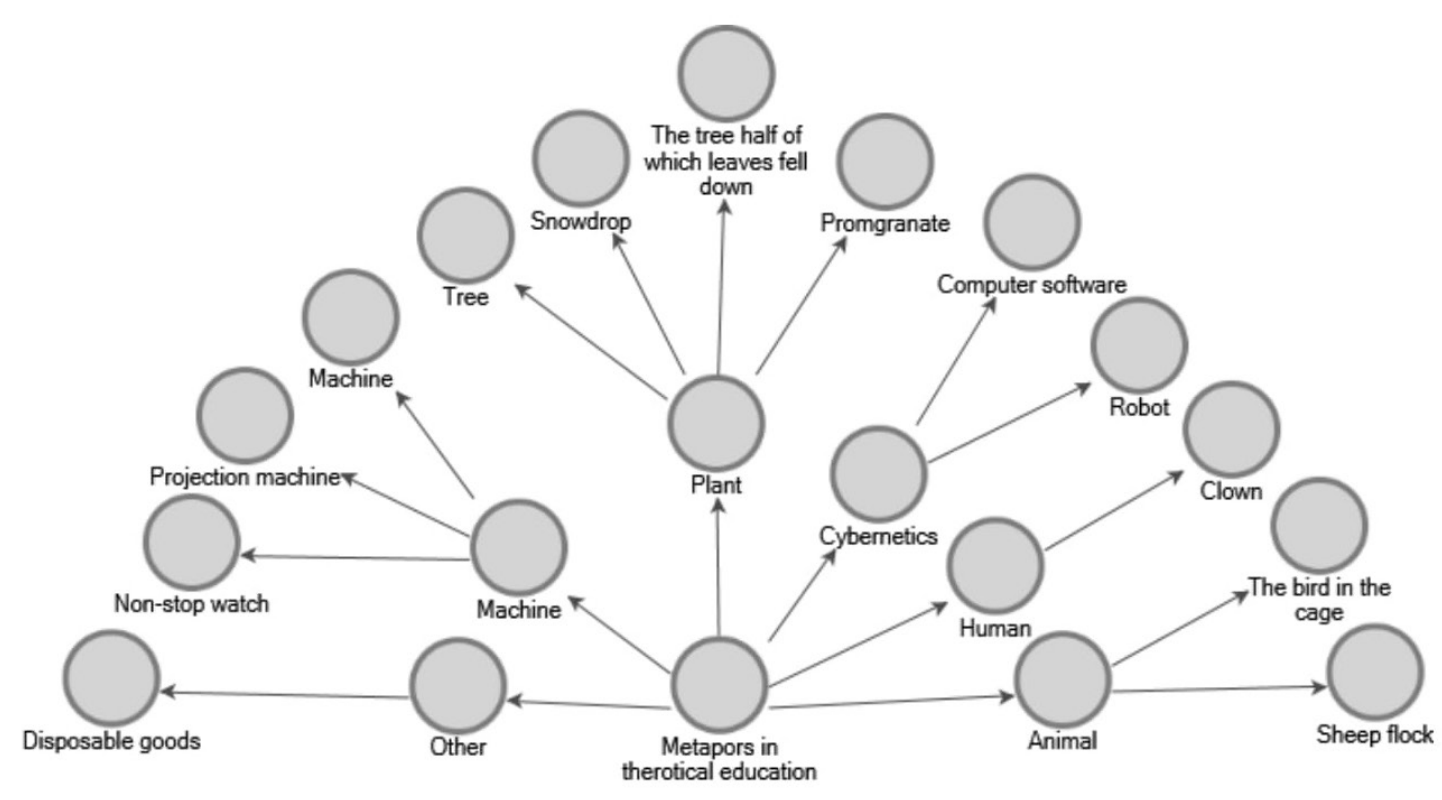

Figure 1. Thematic analysis of metaphors on theroretical education. 
The study under the findings of the theoretical education problems revealed one of the sub-themes as instructors' insufficient effective class management. Kaya ${ }^{13}$ stressed the problems related to lecturers in theoretical education and commented that active attendance and activities for students to question were not used sufficiently. Additionally, participants stated the problems with measurement and evaluation showed that they comprehensively thought about theoretical education. Themes, such as "nursing education's being far from making the students enjoy nursing profession" and "the insufficiency of nursing aspect in the subjects of courses," can present that nursing students thought about the insufficiency of autonomy in nursing. In the historical development of the nursing profession, autonomy has been a major problem in the studies. ${ }^{14,15}$ Thus, it can be thought that nursing students were worried about the autonomy of nursingbefore working as a nurse.

When participants' views on factors that facilitate theoretical education are commented on, the sub-themes, such as theoretical education completion with laboratory practice and description of clinical experiences by lecturers in the course, are significant findings. Participants wanted to hear real sample cases in nursing applications and gave importance to seeing settings similar to real ones that could explain the importance of practical nursing. Accordingly, Dreyfus and Dreyfus ${ }^{16}$, stressed the fact that practice knowledge based on real-life experiences has more didactic factors compared with theoretical knowledge in courses. The other themes, such as "classification of the curriculum according to the principle from simple to complex," "planning theoretical courses before clinical practice," "sufficiency of physical conditions and technical equipment," and "using of remarkable methods in teaching," were related to effective classroom management in terms of planning teaching methods used in course that supply suitable teaching materials and physical environment.

When participants' views on recommendations for theoretical education are generally analyzed, methods to enhance learning are the recommendation that is the most stated by participants. Findings on views by students also revealed that the sufficiency of lecturers affected the quality of theoretical education in nursing. The literature mentioned that nursing student expected theuse of the right teaching strategies, methods, and techniques in theoretical courses. ${ }^{7,8,17}$ The study by Atasoy and Sututemiz ${ }^{8}$ revealed that lecturers' being active in courses was one of the most desired expectations of students, which are consistent with our study results.

It was also understood from participants' views that the subthemes, such as giving up block-scheduling of courses and making laboratory practices more effective, were given priority. Similarly, in a qualitative study by Ewertsson et al. ${ }^{18}$, practices in laboratories built a bridge between theory and practice as stated with the theme of "walking on the bridge."

One another recommendation for the theoretical aspect of nursing education was reducing the number of students in classrooms. Consistent with this finding in the report of the 2017 Nursing Undergraduate Education Workshop, the number of student quotas due to the difficulties experienced related to the over-numbered students both in theoretical and laboratory courses should be reduced as suggested. ${ }^{9}$

Additionally, participants also recommended that positive feedback to students should be given in the courses, and course topics should be taught through case reports. For instance, participant K8 mentioned teaching course topics through case reports as "In my opinion, course topics should be taught through case reports. There should be a case report at the end of each course. We learn much better with a case report." In some studies, students stated that they expected the lecturers to encourage themselves by using case reports in courses. . $^{8,1920}$

As for metaphors, participants produced metaphors for theoretical courses, such as a tree half of that leaves fell, pomegranate, snowdrop, tree, robot, computer software, projection machine, machine, a clock that never stop working, flock of sheep, a bird in a cage, clown, and a thing used once. As it can beunderstood, most participants used metaphors with negative meanings. Only one of the metaphors with a positive meaning shows that students could not autonomously behave. For instance, K5 stated as "I think it is like a bird in a cage. We are in a cage and want to go out. Probably, we want to develop ourselves but we are limited. Anyway, we have wings and we can do something." Additionally, K12 stated "Being a student in this school is like a robot. The system of the school is monotonous. Get up early inthe morning, go to school, again return home, go to bed, sleep, get up and go to school, and so on. You are as if you were turning the same wheel." In a study by Karagozoglu et al. ${ }^{21}$, it was similarly revealed that the autonomy level of nursing students was lower than required.

\section{CONCLUSION}

Our study results revealed the problems in the theoretical aspect of nursing education and their recommendations to solve those problems through views of students based on their perspectives. Students' views can contribute to the studies to improve and develop nursing education.

\section{Implications for Nursing Education}

Our study results can put forward suggestions related to the theoretical aspect of nursing education to lecturers working in different fields of nursing education. Additionally, those results enable nursing education lecturers to notice their satisfaction, the difficulties they experienced, and their equivalent solutions. 
Nursing students' views on theoretical education can widen the perspectives of lecturers inmanagement and training positions. Participants' negative point of view on block-scheduling of theoretical education is considerable. Students' stating about the difficulties of attending courses, whichwere $8 \mathrm{~h}$ long a day, and how those negatively affected them are evidence for a solution. Students stated that the system of timing in teaching was too difficult for them, they had difficultyin starting courses early in the morning and stopping in the evening, they felt burned outin the evening and they had no spare time for themselves for other activities. Lecturers should notice how difficult for students to attend the courses thought by the same lecturer all day-long, courses became monotonous in this way, students could not understand the course after a while, and the courses taught would become useless. Students themselves should assess the efficiency of the courses they attended to evaluate whether the nursing education has reached its goals. In literature, intensive and day-long course hours were stated as the source of stressors by students. ${ }^{7,12}$ Theoretical education is the basis of practical education and training. Students' views on the problems related to the way courses were taught should be taken care of by lecturers and administrative staff. Since the number of students per class was overcrowded, students stated thatlecturers could not effectively manage classes and they taught courses by using expository instructionmethod, thus they could not attract students' attention.

Additionally, more than half of nursing education consisted of practical education and training, students stated that lecturers did not teach courses with real-life cases or the nursing aspect in the content of the courses they taught was insufficient.

The study by Atasoy and Sututemiz ${ }^{8}$ revealed that nursing students experienced problems related to the way lecturers taught courses and originating from lecturers themselves. The feedback from students will help to plan and carry out improvement in activities for nursing education as the students mention the quality of the education they attended. ${ }^{22}$ Many quantitative studies are done on theoretical education in the literature; however, studies to reveal students' views on theoretical education in-depth are limited. Therefore, the findings of this study can lead to improved lecturers in nursing education. Participants also mentioned their views reflecting their satisfaction related to theoretical education. Students stated that lecturers' explaining about sample cases in courses and telling narratives from real-life events improved their learning, which enabled students to imagine the case. They also stated that supporting theoretical education with skill trainingin laboratories was very useful. Studies in the literature concluded that practices are done in clinical skill laboratories supported theory and practice and established a bridge between two aspectsof nursing education. ${ }^{18}$ Taking those views into consideration, planning and sustaining nursing education is extremely important. Thus, to support nursing students' levels of professional autonomy and creativity, education and training methods conducted in education faculties should be re-examined and improved. These findings can positively contribute to long-term outcomes, such as enhanced nursing education quality, improved theoretical nursing education aspect, qualified care applications, more economical health care systems,and patients care.

\section{Main Points}

- Theoretical education is the basis of practical education and training.

- It can contribute to the development of the nursing education curriculum.

- The improvement and development of the theoretical aspect of nursing education positively affect the practice.

\section{Acknowledgements}

We gratefully acknowledge the nursing students who participated in this survey for their time and sharing their opinion and experience.

\section{ETHICS}

Ethics Committee Approval: This study was initiated with the permission of the Faculty of Nursing and the approval of the Clinical Researches Ethics Committee of Akdeniz University (date: 01.03.2017; approval number: 137).

Informed Consent: A consent form was signed between the researcher and each participant on the use of data for analysis to be reported and disseminated.

Peer-review: Externally peer-reviewed.

\section{Authorship Contributions}

Conception: L.M., S.S., I.G.; Design: L.M., S.S., I.G.; Data collection; L.M., S.S.; Analysis and/or Interpretations; L.M., I.G.; Writing: L.M., S.S.

\section{DISCLOSURES}

Financial Disclosure: The author declared that this study had received no financial support.

Conflict of Interest: The authors declare no conflict of interest.

\section{REFERENCES}

1. Bolukbas N. The socio-demographic characteristics and opinions conected with education of the students in ordu health school. J Anatolia Nursing Health Sci. 2016;9:49-57.

2. Mehrdad N, Bigdeli S, Ebrahimi H. A comparative study on self, peer and teacher evaluation to evaluate clinical skills of nursing students. Procedia: Social and Behavioral Sciences. Crookes: PA 2012; 47: 1847-1852. Brown RA. What are the 'necessary' skills for a newly graduating RN? Results of an Australian survey. BMC. 2016;151-158. 
3. Betch U, Charles K, Sean E, Cherilyn Hipps A, Larissa Marquez A, Michael LC. Improving retention, confidence, and competence of new graduate nurses: Results from a 10-year longitudinal database. Nursing Economics. 2010;6:363-376

4. Frenk J, Chen L, Bhutta ZA, et al. The Lancet Commissions: Health professionals for a new century: Transforming education to strengthen health systems in an interdependent world. Lancet. 2010;376:1923-1958.

5. Bvumbwe T, Mtshali N. Nursing education challenges and solutions in Sub Saharan Africa: An integrative review. BMC Nurs. 2018;17:3. doi: 10.1186/ s12912-018-0272-4

6. Bayik A. (Quality approach to nursing research II. National nursing research symposium book, Odak ofset, Ankara, 61-79; 2004.

7. Bagcivan G, Cinar FI, Tosun N, Korkmaz R. Determination of nursing students' expectations for faculty members and the perceived stressors during their education. Contemp Nurs. 2015;50:58-71.

8. Atasoy I, Sututemiz N. A group of final year students views on nursing education. Florence nightingale. J Nurs. 2014; 22:94-104.

9. Yuksekogretim kurumu [Council higher education], (YOK. [COHE]); 2017. Undergraduate education symposium in nursing [internet]. (cited 2017 December 23). Available at: http://www.yok.gov.tr/web/guest/hemsireliklisans-egitimi-calistay-raporu-yayimlandi

10. Yin R, Gunbayi I. Application of case study research (Durum calısmas arastırması uygulamaları). 3rd edition. Nobel: Ankara; 2017.

11. Cohen L, Mannion L, Morrison K. Research methods in education.UK. Routledge, Taylor \& Francis Group: London; 2007.

12. Burnard P, Edwards D, Bennett $\mathrm{K}$, et al. A comparative, longitudinal study of stress in student nurses in five countries: Albania, Brunei, the Czech Republic, Malta and Wales. Nurse Educ Today. 2008;28:134-145.
13. Kaya $\mathrm{H}$. The problem of theoretical education in nursing education programs. Florence nightingale. J Nursing. 2016;24:175-180.

14. Farrell GA. From tall poppiest osquashedweeds: Why don't nurses pull together more? J Adv Nurs. 2001;35:26-33.

15. Ekinci M, Sahin Altun O, Can G. Examination of the coping style with stress and the assertiveness of the nursing students in terms of some variables. $J$ Psychiatr Nurs. 2013;4:67-74.

16. Dreyfus HL, Dreyfus SE. The relationship of theory and practice in the acquisition of skill. In: Expertise in nursing practice: Caring, clinical judgment, and ethics Benner PA, Tanner CA, Chesla CA, editors. Springer: New York. 29-47; 1997.

17. Karadag G, Sapci E, Pekmezci S. Thought and expectations of nursing students through education and professional. Gaziantep Med J. 2015;21:26.

18. Ewertsson M, Allvin R, Holmström IK, Blomberg K. Walking the bridge: Nursing students' learning in clinical skill laboratories. Nurs Educ Pract. 2015; 15:277-283.

19. Ewertsson M, Allvin R, Holmström IK, Blomberg K. Clinical skill laboratories. Nurse Educ Pract. 2015;15:277-283.

20. Çamveren H, Dursun Engin M, Erdem Ç, Vatan F. Expectations of nursing students about the quality of services offered by the instructors. Int Refer J Nurs Res. 2015;2:53-70.

21. Karagozoglu S, Karagözoğlu S, Türk G, Özden D. Autonomy levels of final year baccalaureate nursing students attending different curricula: Cross-sectional survey. Cumhuriyet Med J. 2015;37:87-101.

22. Alan N, Khorshid L. The Opinions of nurses graduated from faculty about bachelor's degree education and affected factors. I Anatol Nurs Health Sci. 2015;18:87-93 